\title{
As "falhas" que tecem o Haiti
}

Cristine Koebler Zanella

$\mathrm{D}_{\mathrm{d}}$ O CONJUNTO de poeira e escombros do terremoto que em 12 de janeiro de 2010 atingiu a região metropolitana da capital haitiana, Porto Príncipe, ergue-se, altivo, o testemunho Falhas, de Yanick Lahens. O livro foi originalmente publicado em francês, em 2010, sob o título Failles, por Sabine Wespieser Éditeur. Em 2012, vertido para o português em trabalho dedicado e sensível do embaixador Sérgio Duarte e prefaciado por Ricardo Seitenfus, a Fundação Alexandre de Gusmão (Funag) fez que o texto chegasse ao Brasil por meio impresso. Posteriormente o trabalho foi disponibilizado integralmente em meio digital, na página institucional da Funag na internet.

Como o título sugere, "Falhas" tem como epicentro do qual fluem escrita e ideias o sismo de 12 de janeiro. Nessa tragédia humanitária, em pouco menos de 40 segundos o movimento de placas tectônicas vitimou de morte cerca de 222 mil pessoas, deixou aproximadamente 300 mil feridas e, no pico de gravidade da situação, mais de 2,3 milhões desabrigadas - isso em uma população total de aproximadamente nove milhões de habitantes (OSGSA/UN, 2013). Muito além dos números, o testemunho de Yanick Lahens desdobra a dimensão pessoal, humana e sensível do terremoto para, a partir dela e sempre por meio da literatura, refletir sobre as grandes inflexões que forjaram o Haiti enquanto estado e nação.

A dimensão de testemunha das dores do corpo e do espírito haitianos é uma marca que perpassa todas as páginas do livro. Yanick nos oferece, crua, a sua memória atormentada com o grito profundo e ecoante da menina que perdia a perna amputada sem anestésicos. Ela divide com o leitor a sua intimidade, compartilhando a ansiedade de precisar utilizar um cômodo da casa cujas estruturas estavam comprometidas.Ela nos presenteia com a emoção de saber que um pai, preso entre as ferragens, ao ver sua vida se esvair, conseguiu falar com os filhos ao telefone e legar-lhes algumas últimas palavras. Acima das estatísticas - que, paradoxalmente, quanto mais expressivas, menos nos são sensíveis -, Yanick Lahens nos dá, assim, a dimensão humana do terremoto de 2010 e nos obriga, com redação direta e palavras fortes, a andar por entre seus escombros sem muletas.

A dimensão humana desenhada está longe de ser, porém, um rosário interminável de dores. Ao contrário. As palavras fortes e pungentes de Yanick Lahens travam desde o início uma luta com a tragédia, para que esta não saia vitoriosa sobre a literatura, enquanto arte, e sobre um povo, enquanto membro indissociável da humanidade:

Como escrever evitando tornar exótica a desgraça, sem fazer dela uma oportunidade de sedução, um objeto de comércio, artigo de exibição em uma feira? Como colocar-se à altura da desgraça? [...]

Escrever para repatriar a desgraça ao lugar que lhe cabe. O centro. Porque o que se abateu sobre nós no dia 12 de janeiro não é uma desgraça de periferia, uma desgraça do "quarto 
mundo". É uma desgraça de primeiro mundo, assim como de todos os outros. Meu amigo, o escritor Émile Olivier, hoje falecido, dizia de seu exílio em Montréal: “Todas as manhãs, acordo com uma dor lancinante. Não adianta tomar analgésicos, não consigo livrar-me dela e a cada manhã ela me agarra pela garganta: Haiti, Haiti, como vai tua dor?". Precisamos fazer-nos essa mesma pergunta, porém estendê-la ao mundo: "Bom dia, mundo, como vai tua dor?”. (p.20)

Em sua luta contra a vitória da desgraça a narrativa da escritora caribenha nos eleva por cima do terremoto para contemplar, do alto, seus efeitos. Mas essa mesma narrativa também se utiliza do sismo - e assim o supera - para nos falar do padrão das relações internacionais que desde muito cedo se estabeleceram com o país. Pergunta-se, por exemplo, porque tanta negação ante os alertas lançados pelo sismólogo Claude Prépetit sobre o terremoto, se tantos sabiam que a capital já tinha sido destruída duas vezes, no século XVIII? À negação desses alertas simplesmente porque a terra abaixo não se movia, a autora contrapõe muitos outros fenômenos negados simplesmente porque não estão chacoalhando, permanentemente, a superfície. Na dimensão mundial, nossa negação generalizada com os problemas do planeta comum que habitamos; na dimensão haitiana, as grandes falhas estruturais políticas, econômicas e sociais. Na dimensão haitiana histórica, a punição do país pela ousadia de se fazer independente pelas mãos de escravos. Excluída do "concerto das nações" pelas potências escravagistas e colonialistas inconformadas com a insolência da independência negra, essa experiência já era um prelúdio a ensaiar as experiências das relações internacionais que seriam mais tarde chamadas de Norte-Sul.

O trabalho árduo que diversos quadros de trabalhadores e trabalhadoras do Haiti vinham desempenhando apesar de todos os percalços econômicos é lembrado e a sua memória salva nas páginas de Falhas. Trabalho e dedicação que tenderiam a ser esquecidos em meio aos discursos de incompetência e inaptidão absoluta de toda a administração haitiana que se encaixam melhor em um país falido. Como observadora privilegiada, que estudou no exterior e que teve experiência com associações internacionais, Lahens posiciona-se e aproveita para lembrar que esse discurso de país falido, quebrado, sem esperança, savana e quilombo entre os demais espaços do mundo, serve bem aos propósitos de alguns atores políticos nacionais e internacionais (entre os quais as $\mathrm{ONG}$ ). Para muitos desses serve mais - e há séculos - a imagem de um Haiti bestial e incapaz em vez de um país corajoso, líder de seu destino e que luta para se colocar em pé apesar de todas as dificuldades; serve mais a imagem de um país indomável do que um com o qual é possível dialogar e construir em conjunto. Esse discurso alimenta diversas lógicas: a da dependência, a das diferenças baseadas na cor e até mesmo a da ajuda internacional. Reproduzidas ao infinito elas encerram em si uma lógica de poder que acaba por perverter qualquer polo da relação. Para a autora, enquanto essas lógicas não forem refundadas o sismo será mais uma das falhas a forjar o histórico de tragédias haitianas, não a mais severa de todas e nem a derradeira.

As estruturas que o terremoto escancarou são, portanto, muitas outras além daquelas que se expuseram entre escom- 
bros - muito embora esses denunciem, vergonhosamente, a pobreza haitiana. Essas outras estruturas com falhas escancaradas são também as de instituições, as da comunidade internacional e as dos países que se fazem presentes nas terras haitianas. Yanick Lahens expõe na redação de seu texto sem pudores e de forma cristalina o intrigante embate de interesses de grandes atores internacionais que se projetam sobre uma terra de nove milhões de habitantes, 27 mil quilômetros quadrados e mais algumas centenas de milhares de mortos.

Há os americanos, visivelmente desejosos de retomar o controle sobre certo número de temas-chave; há uma América Latina, com a Venezuela e Cuba, e outra com o Brasil, que joga sua entrada no Conselho de Segurança e seu poderio na região. Há o Caribe. Há a União Europeia, distante. Há a República Dominicana, que gostaria de trabalhar com Cuba e em outro quadro com os Estados Unidos e a Europa. Há a França, com a qual desde nossa independência sempre tivemos relações tumultuosas, que seria útil esclarecer. Há a grande China, ainda mais longe, que aspira a um voto suplementar nas $\mathrm{Na}-$ ções Unidas e um pé na bacia caribenha. Há a outra China, que pretende o mesmo voto e o mesmo pé. Isso basta para provocar vertigem. (p.73)

Sem retirar a responsabilidade dos haitianos - que endereça ao tratar do homo economicus e do homo politicus haitiano -, nessas passagens, faz-nos pensar sobre a procedência dos discursos criados sobre o Haiti e sobre a legitimidade da natureza das principais ações da Minustah: Missão de Paz que atua fortemente escorada em um braço militar num país que não está em guerra e cuja maior vergonha - ou obscenidade, nas palavras de Yanick - é a pobreza.

Nas páginas de Falhas, Yanick Lahens também ergue, registra e, assim, eterniza inúmeros aspectos da cultura haitiana. Há dois deles que recordo terem me chamado a atenção quando visitei, em 2009 , o país: o movimento agitado das cerimônias fúnebres e os ensinamentos transmitidos pelos anciãos por meio da palavra falada. Não caberia a um estrangeiro - ao menos sentia que não caberia a mim -, porém, registrá-los. O terremoto nos legou esse registro. No primeiro caso, Yanick descreve com estranhamento a ausência de gritos e lágrimas na partida dos mortos, porque os mortos haitianos não partem nunca em silêncio. Relato que revela as razões profundas do trauma coletivo gerado por tantas centenas de milhares de mortos enterrados, sem barulho e sem cerimônia: "Habituamos nossos mortos aos lamentos das carpideiras, aos risos, à agitação, ao rum e às histórias contadas nos velórios, aos percursos em ziguezague até os cemitérios para perdê-los no caminho, a fim de que eles não regressem por muito tempo para nos importunar sem motivo" (p.56).

No segundo episódio somos informados da lodyans: uma rica tradição de transmissão de conhecimentos e de saberes cujas origens se perdem nos séculos. Tradição oral. Ela está na raiz da compreensão da história e do lugar dos haitianos no mundo e talvez justamente porque ela - palavra oral destinada a alguns escolhidos - é reservada aos que os anciãos creem poder compreendê-la e honrá-la é que um estrangeiro sente sempre o Haiti tão fascinante quanto indecifrável:

S. é um dos que vem todos os sábados pela manhã. É um ritual de trans- 
missão. Devido à diferença de idade, eu faço parte daqueles e daquelas que recebem lições de vida. S. é um dos raros homens que se dedicaram à política e deixaram uma imagem digna. Tem a cabeça erguida, o coração de pé, possui coluna vertebral. Conservamos uma tradição da palavra, a lodyans, que remonta ao passado distante e que ainda se pratica em algumas cidades do interior e nas galerias de Port-au-Prince. (p.72)

Com o terremoto de 12 de janeiro de 2010, de alguma forma, nos tornamos todos um pouco haitianos, mas a velocidade e a quantidade de informações tendem a esmaecer esse pertencimento da nossa memória. Daí a importância de ler o testemunho de Yanick Lahens. Suas palavras escritas contribuem para não nos esquecermos da centralidade do Haiti enquanto matriz de inúmeros padrões de relações internacionais e enquanto exemplo contundente das potencialidades humanas levadas ao extremo, apesar de todas as tragédias. Ao legar-nos essa contribuição, a autora caribenha vence o desafio autoimposto de não sucumbir ao sismo, mas de superá-lo à medida que o registra e o expõe, recolocando-o em seu lugar no tempo e no espaço e retirando o Haiti da periferia da História. Pelas páginas de Falhas, Yanick Lahens, ao narrar o terremoto, fez o Haiti emergir enquanto "metáfora do mundo e metáfora da modernidade".

Referências

LAHENS, Y. Yanick Labens - Failles. 2:13'. 2012 Disponível em: <http://www.youtube.com/watch? $=S 2 q 41 \mathrm{QW} 2 \mathrm{UbQ}>$. Acesso em: 25 abr. 2014.
OSGSA/UN [Office of the Secretary General's Special Adviser/United Nations]. Key Statistics: Facts and figures about the earthquake, cholera, and development challenges in Haiti. Disponível em: <http://www.lessonsfromhaiti. org/relief-and-recovery/key-statistics/>. Acesso em: 15 dez. 2013.

LAHENS, Y. Falhas. Trad. Sérgio Duarte. Brasília: Funag, 2012. 123p.

Cristine Koehler Zanella é doutora em Ciências Políticas (UGent/Bélgica) e em Estudos Estratégicos Internacionais (Universidade Federal do Rio Grande do Sul). @ - cristine.zanella@ufrgs.br

Recebido em 29.4.2014 e aceito em 30.7.2014.

${ }^{\text {I } U n i v e r s i d a d e ~ F e d e r a l ~ d o ~ R i o ~ G r a n d e ~ d o ~}$ Sul. Porto Alegre/Rio Grande do Sul, Brasil. 